\title{
IMPLANT SATBILITY AND PERI-IMPLANT MARGINAL BONE LOSS AROUND TWO DIFFERENT THREADS DESIGN IMPLANTS
}

\author{
Maha Nagy Mohamed Kamal ${ }^{*}$
}

\begin{abstract}
The aim of this study was to evaluate implant stability and the peri-implant marginal bone loss around two different threads design implants; conventional macro-threads design implants and crestal micro-threads design implants.

Materials and methods: A total of 14 implants of $3.5 \mathrm{~mm}$ diameter $\times 11.5 \mathrm{~mm}$ length having two different threads designs were divided into two groups, $(n=7)$ : group A; implants with conventional macro-threads design and group B; implants with crestal micro-threads design were placed in maxillary permolar area in partially edentulous patients. Stability was evaluated by insertion torque and resonance frequency using an Osstell device at baseline (time of implant insertion), 15, 30, 45 and 60 days follow up periods, while peri-imlant marginal bone loss was measured by CBCT taken at baseline (time of implant insertion) 3, 6,12 and 18 months (one year after loading) follow up periods.
\end{abstract}

Results: At the end of follow up period, group B (Implants with crestal micro-thread design) showed statistically significant higher mean values regarding primary and secondery implant satbility inaddition to statistically significant lower mean values regarding peri-implant marginal bone loss when compard to group A ( implants with conventional macro-threads design).

Conclusion: Implants with crestal micro-thread design showed better stability and less periimplant marginal bone loss than the conventional macro-threads design implants.

KEYWORDS: Marginal bone loss, implant design, implant stability, micro-thread Implant.

\section{INTRODUCTION}

A lot of efforts were done to improve the relationship between bone and implant to ensure the long term successs of osseointegration of dental implants and to enhance clinical performances ${ }^{1}$.
Studies were conducted on the design and surface treatment of implants with a lot of chemical and mechanical surface modifications to ensure osseointegration quality improvement with less postsurgeical complicatioans and shortened healing period. ${ }^{1,3}$,

\footnotetext{
* Lecturer of Removable Prosthodontics Department, Faculty of Dentistry, British University in Egypt (BUE).
} 
A successful implant treatment depends significantly on the implant primary stability which considered as a powerful factor with huge influence on implant secondery stability and subsequently on osseointegration. ${ }^{4-6}$ therefore, the macro geometry modifications of the implant fixtures promoted greater surface area and contact between bone and implant, with increased primary stability and reduction of bone anchor related failures. ${ }^{7,8}$

There are two main implant designs, the macrodesign which is related to implant thread geometry and fixture shape, while the microdesign which refered to implant material and surface treatment. ${ }^{9}$

Implant body surface can be classified into threaded and non-threaded surfaces. It is believed that threads have a mandatory effect on stability and long-term performance of dental implants as it maximize primary implant/bone contact, increase implant surface area, help stress distribution over the bone and enhance primary stability. ${ }^{2}$

Moreover, the concept of double threaded or triplethreaded implants has been recently introduced

and is believed to provide faster thread penetration into the bone, generate less heat upon placement and improve primary stability. These implants require more torque for placement thus have tighter contact with bone, which could be indicated for type IV (cancellous) bone. ${ }^{10}$

Studies showed that the mechanical simulation provided by threads on the implant neck area is required to preserve the marginal bone level with confirmation of the advantages of microthread on the coronal portion of implant fixture compared with a smooth neck fixture regarding the established bone-to-implant contact and marginal bone level maintenance ${ }^{11,12}$.

In contrast, few clinical studies have mentioned the role of thread size, or thread pitch distance, on the maintenance of the peri-implant marginal bone level, when the threads were positioned to the fixtures neck. Thus, the aim of this clinical investigation was to evaluate and to compare the influence of crestal thread design having two different sizes (macro and micro) on implant stability (primary and secondery), and on the periimplant marginal bone loss around implant fixtures.

\section{MATERIALS AND METHODS}

Patients who required implant therapy were selected from the removable prosthodontic clinic, faculty of dentistry, British University of Egypt (BUE). All patients were medically free and in good general health, with age range: 37 to 50 years, with the following inclusion criteria; (1) presence upper partially edentulous arch with missing one or more of premolar teeth opposed by fully dentated mandibular arch. (2) minimum bone height $14 \mathrm{~mm}$ and minimum bone width $6 \mathrm{~mm}$ to ensure implant placement without any sinus lifting or ridge augmentation. (3) healed bone sites with at least 6 months having elapsed from the last tooth extraction. However, patients with systemic and / or bone diseases such as osteoporosis, uncontrolled diabetes mellitus and hypertension were excluded from the study. Patients were also excluded if the insertion torque of the placed implants (IT) $\leq 35$ $\mathrm{Ncm}$, or if the treatment would cause a risk to the patient's health, or if patient's cooperation appeared questionable, and/or the patient did not consent to participate.

Prior to entry into the study, each patient provided informed consent to participate.

\section{Treatment procedures:}

Sample allocation: Patients were randomly assigned into two identical groups by using special website concerned with randomization process called research randomizer (https://www. randomizer.org/). All surgeries were performed using a two-stage method. Implants from each group 
were placed in maillary premolar area in partially 0.5 edentulous patients. The implants were placed $\mathrm{mm}$ subcrestally per the manufacturer's guidelines, and special attention was paid to ensure that there $1 \mathrm{~mm}$ or more of bone remaining both buccally was and lingually. The second surgery was performed 3 months later and the prostheses were delivered 6 weeks after the second surgey in the form of fixed .crowns

A total of 14 SIC dental implants ( Schilli Implantology Circle, Germany) of $3.5 \mathrm{~mm}$ diameter $\times 11.5 \mathrm{~mm}$ length) divided according to the implant design into two groups ( $\mathrm{n}=7)$; Group A: SIC ace with conventional threads design with uniform thread pitch from the apex to the neck area. and Group B: SIC max with crestal microthreads design with smaller thread pitch in the neck area were placed in maxillary permolar area. Both implant groups had the same implant abutment connection (Integrated "platform switching" with inner precision hex having long guide surfaces for maximum stability of the implant-abutment interface and a screw connection protected against continuous loading), with similar self-tapping screw design and surface treatment (Blasting Procedure with round zirconia particles followed by acid cleaning) which called surface conditioning with a moderate roughness. Fig. 1,2

The preoperative examinations included medical history, dental history, clinical examination, and finally radiographic examination via cone beam computed tomography (CBCT) (scaora 3D X. Filand) was taken to evaluate and measure the available bone width and height at the maxillary premolar area, to virtually plan the implant position in relation to the surrounding structures and to construct the surgical guide Fig. 3,4. Drilling sequence protocol was performed following the manufacturer's recommendation, Fig 5. After osteotomy preparations has been completed, implants were placed $0.5 \mathrm{~mm}$ below the crestal bone, insertion torque values were determined as the maximum torque value $(\mathrm{N} / \mathrm{cm})$ reached at the end of the insertion of the implant in the recipient site.

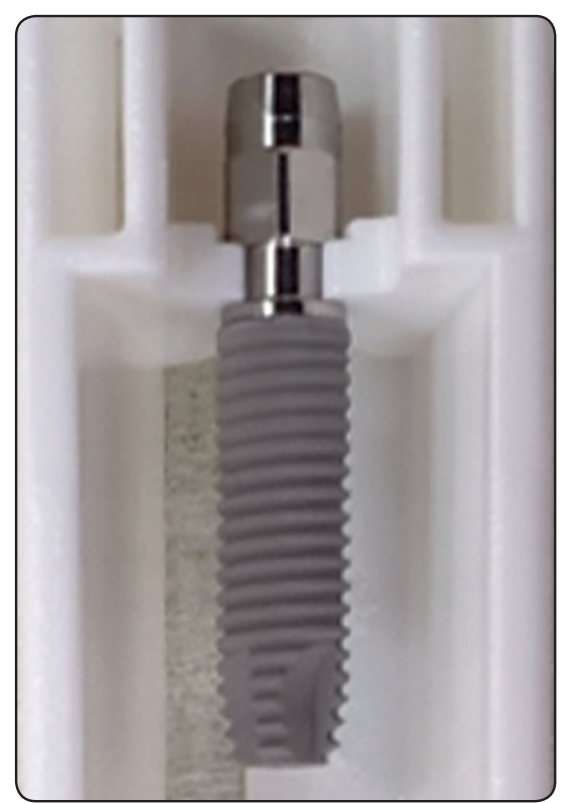

Fig. (1): SIC ace (conventional design)

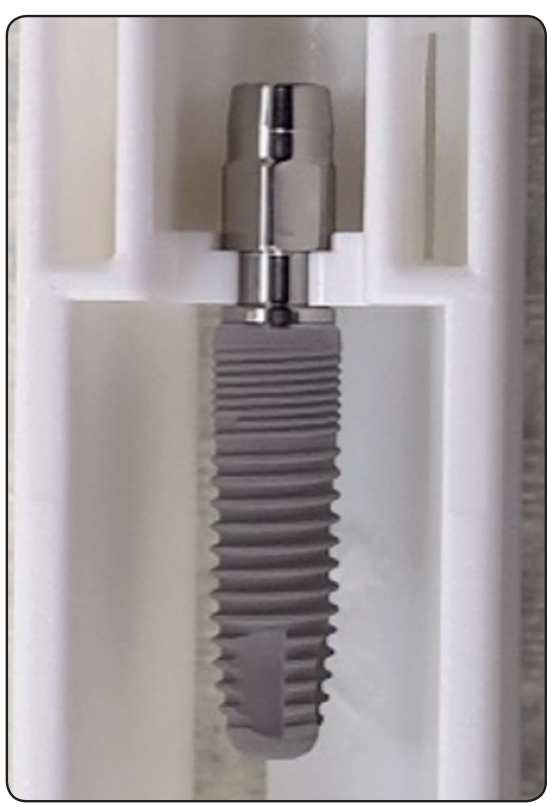

Fig. (2): SIC max (micro-threads design) 


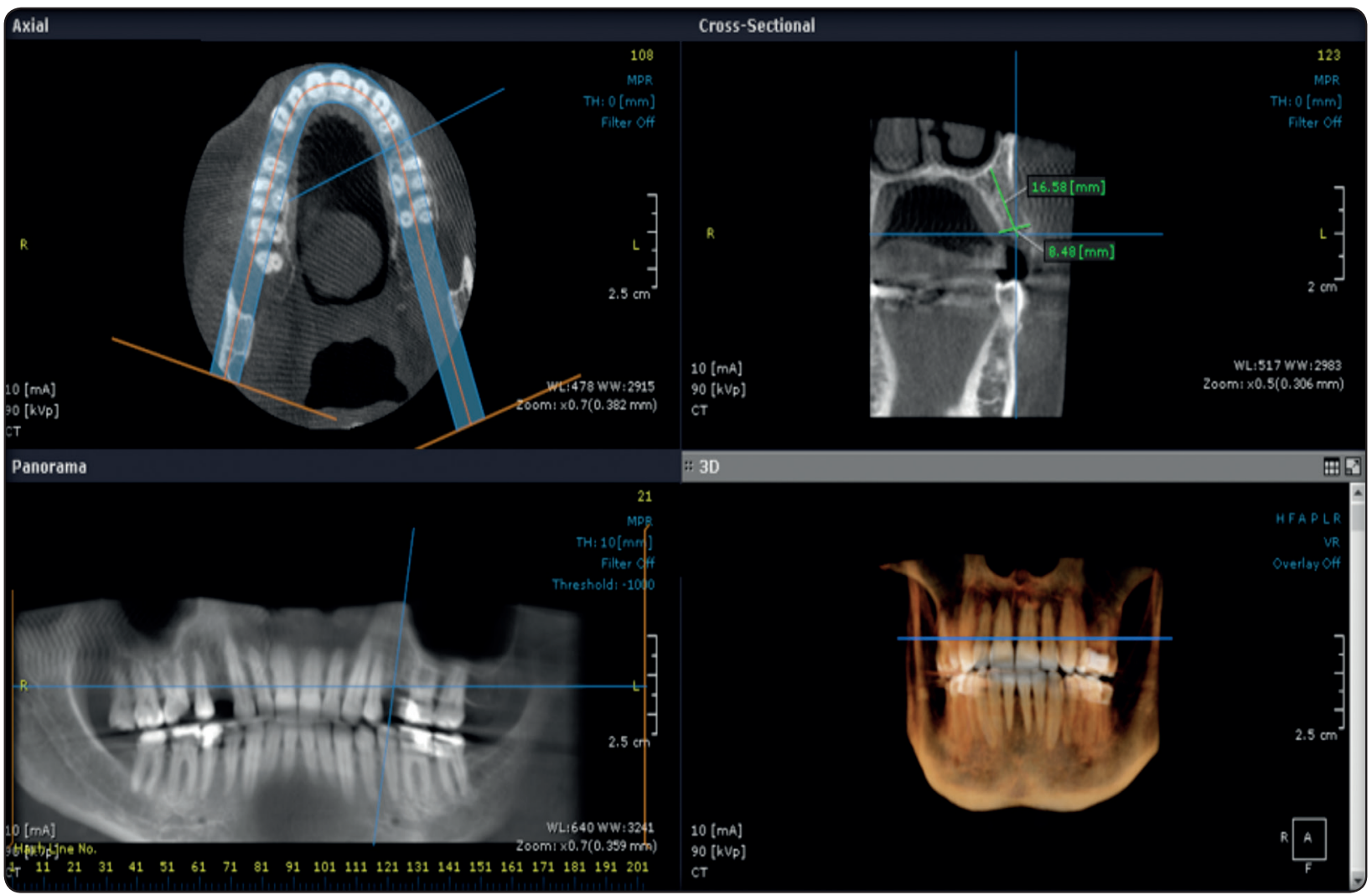

Fig. (3): Preoperative CBCT

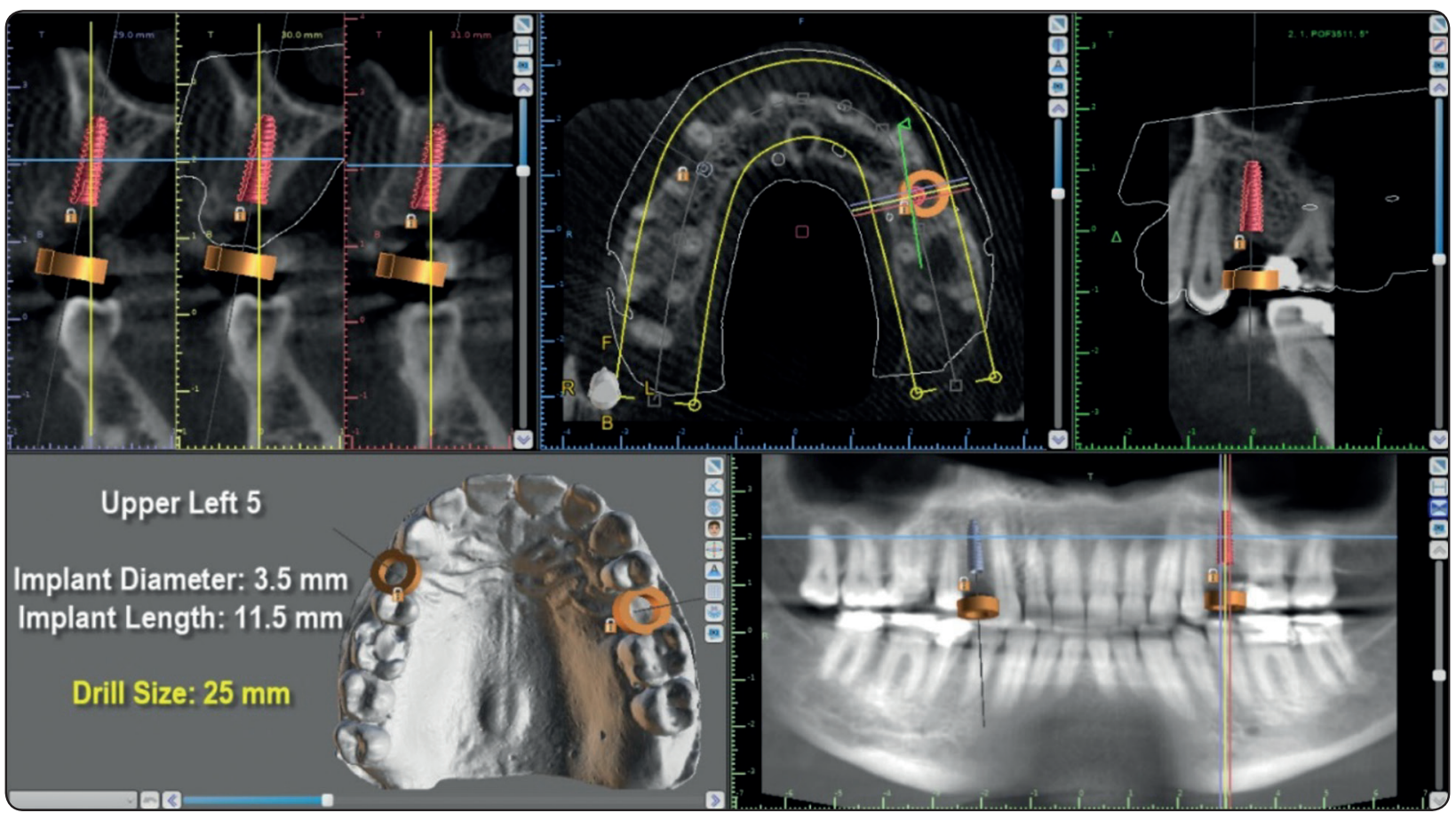

Fig. (4): Virtual planning of implant position. 


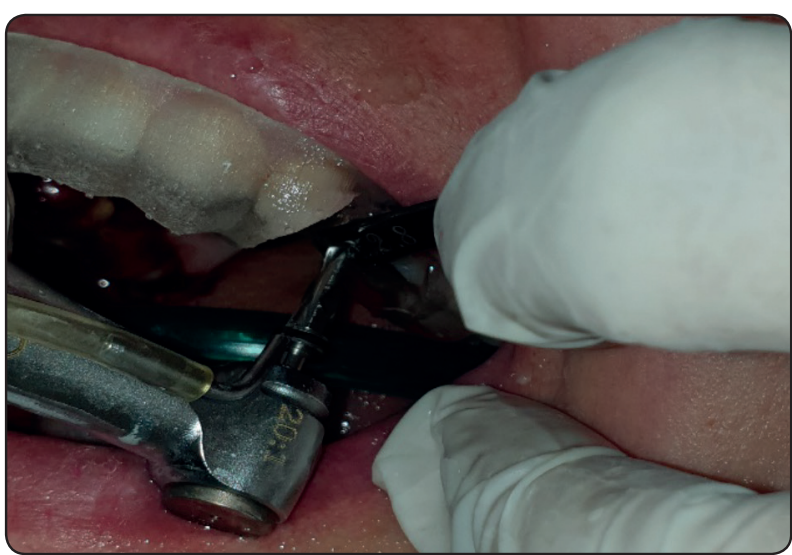

Fig. (5): Drilling through the surgical guide

\section{Primary stability}

Was evaluated firstly by insertion torque of the placed implants (IT) $\leq 35 \mathrm{Ncm}$ during implant placement, moreover, resonance frequency analysis (RFA) was recorded using an Osstell Mentor device (Ostell/Integration Diagnostics, Goteborg, Sweden). The frequency transducer (SmartPeg) was connected to the implants in a uniform manner perpendicular to the alveolar crest. Implant stability quotient (ISQ) was measured four times for each inserted screw (buccal, lingual, mesial, and distal) oriented perpendicular to the transducer as recommended by the manufacturer. Fig 6 . The clinical range of ISQ has been found to be normally at 50 to 80 for implant stability. The secondary stability (SS) was recorded postoperatively at 15,30,45 and 60 days. These intervals were chosen in order to investigate the progression of ISQ during healing time, until complete bone healing. ${ }^{13}$

A second surgery was performed 6 months later. The prostheses were delivered 3 weeks after the second surgery. Oral hyeigin measures and peroidic plaque control together with recording any clinical variables such as such as pain from implant regions, implant stability, gingival inflammation or/ and suprastructure complications were recorded from the day of implant insertion and during the followup periods. ${ }^{14}$

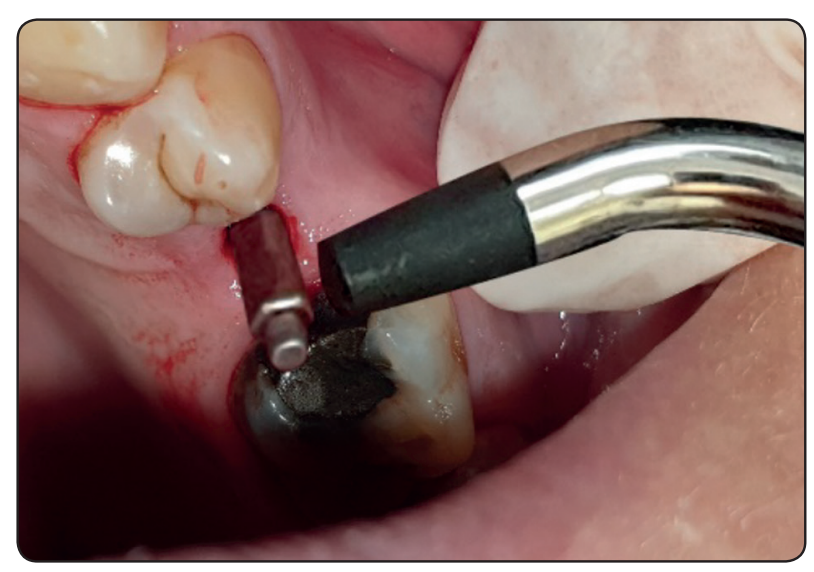

Fig. (6): implant stability quotient ISQ measurements.

\section{Radiographic evaluation:}

CBCT image was taken at the day of implant insertion (baseline). For standardization: volume reorientation was done by making the long axis of the implant perpendicular on the axial reference line, while coronal plan standardization was assured by adjusting the coronal cut at the middle of the implant followed by drawing a line tangent to implant apex, bone length buccal and lingual to the implants was measured from the tangent line to the most crestal level of the bone in contact with the implant surfaces, finally sagittal plan standardization was done by adjusting the sagittal cut at the middle of the implant followed by drawing a line tangent to implant apex, Bone length mesial and distal to the implants was measured from the tangent line to the most crestal level of the bone in contact with the implant surfaces Fig 7. Another CBCT images were performed at 6,12 and 18 months using the same parameters and the same machine, periimplant marginal bone loss around implant surfaces throughout the follow up periods was calculated, tabulated and statistically analyzed.

\section{Statistical analysis:}

Statistical analysis was performed using IBM SPSS Statistics Version 2.0 for Windows. Data was presented as mean and standard deviation (SD). The significance level was set at $\mathrm{P} \leq 0.05$. Kolmogorov- 


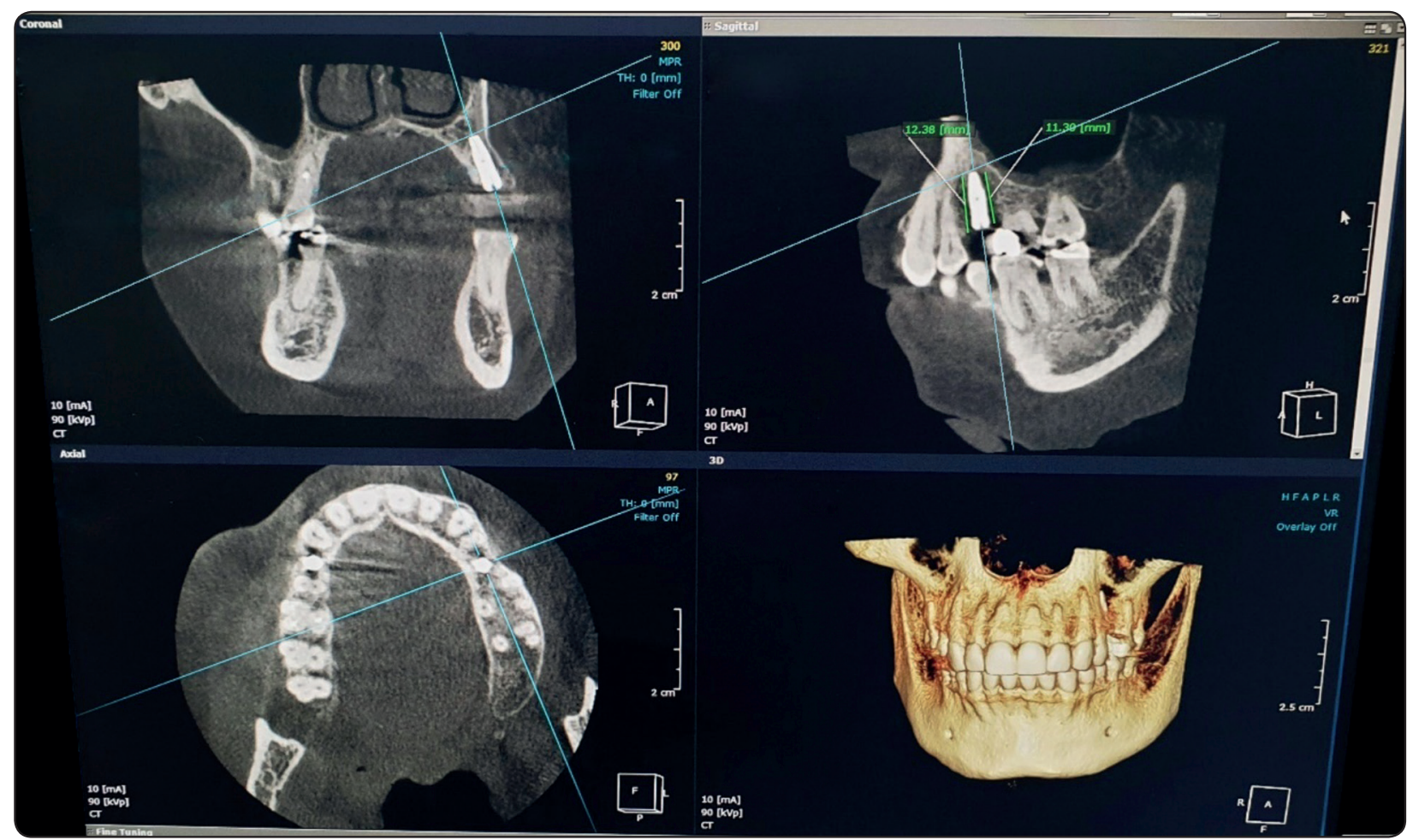

Fig. (7): CBCT after implant insertion with mesial and distal bone height measurements

Smirnov and Shapiro-Wilk tests were used to assess data normality. One-way ANOVA followed by Tukey's post-hoc test were used to compare implant stability quotient (ISQ) and crestal bone height at different follow-up periods within each implant thread design group. Independent Student-t test was performed to compare implant stability quotient (ISQ) and peri-implant marginal bone loss between both implant thread design groups at each follow-up period.

\section{RESULTS:}

Regarding implant stability between both groups, Independent Student test (table 1 and figure 8) showed that group B (crestal micro-thread design implants) displayed significantly highest ISQ mean values compared to group A (conventional macrothread design implants) at all follow-up periods except at 45 days where there was insignificant difference in ISQ mean values.
Regarding implant stability within each group, One-Way ANOVA and Tukey's test displayed that there was a statistically significant difference in ISQ mean values between different follow-up periods within each thread design group. Within group A (conventional macro-thread design implants) ISQ mean values were significantly lowest at 15 days follow up periods, while the 60-days follow-up period represented the significantly highest ISQ which did not differ significantly from that of 45 days. Moreover, there was no significant difference between ISQ values of 30 and 45 days; baseline and 30 days; baseline and 15 days. Within group B (crestal micro-thread design implants) ISQ mean values were significantly highest at 60 days, followed by 45 days, then 30 days which did not differ significantly from baseline. 15-day follow-up showed significantly lowest ISQ values.

Regarding peri-implant crestal bone height changes, Independent t-test (table 2 and figure 9) 
showed that there was no statistically significant difference in bone height mean values between both groups at delivery, 6 months and 12 months. While at 18 months, group B (crestal micro-thread design) yielded significantly higher crestal bone height than group A (convention macro-thread design) ( $\mathrm{P}=0.023)$. One-Way ANOVA and Tukey's

TABLE (1): Mean \pm SD and P-value for the comparison of implant stability quotient values (ISQ) between both groups at each follow-up period.

\begin{tabular}{|l|c|c|c|}
\hline & $\begin{array}{c}\text { Group A } \\
\text { (Conventional } \\
\text { macro-thread } \\
\text { design) }\end{array}$ & $\begin{array}{c}\text { Group B } \\
\text { (Crestal } \\
\text { micro-thread } \\
\text { design) }\end{array}$ & P-value \\
\hline Baseline & $64.75 \pm 1.59^{\mathrm{cd}}$ & $67.87 \pm 1.16^{\mathrm{c}}$ & $0.022^{*}$ \\
\hline 15 days & $61.62 \pm 1.26^{\mathrm{d}}$ & $64.12 \pm 1.53^{\mathrm{d}}$ & $0.047^{*}$ \\
\hline 30 days & $65.43 \pm 1.79^{\mathrm{bc}}$ & $68.06 \pm 0.51^{\mathrm{c}}$ & $0.031^{*}$ \\
\hline 45 days & $68.53 \pm 1.96^{\mathrm{ab}}$ & $70.50 \pm 0.61^{\mathrm{b}}$ & $0.137 \mathrm{NS}$ \\
\hline 60 days & $71.00 \pm 1.44^{\mathrm{a}}$ & $73.43 \pm 1.34^{\mathrm{a}}$ & $0.049^{*}$ \\
\hline P-value & $<0.001^{*}$ & $<0.001^{*}$ & \\
\hline
\end{tabular}

*: significant at $P \leq 0.05 ;$ NS: non-significant at $P>0.05$

Means with different superscript letters within each column are statistically significantly different at $P \leq 0.05$

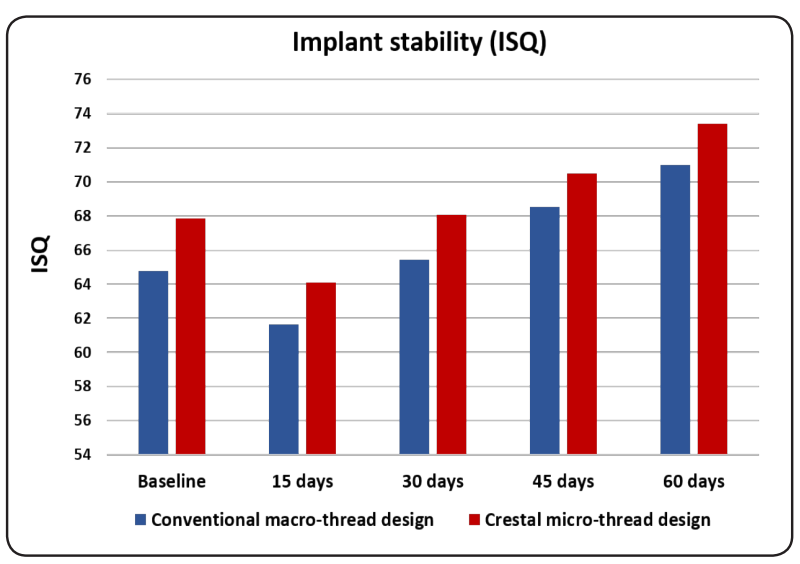

Fig. (8): Column chart showing the ISQ mean values of both groups at different follow-up periods. test revealed that there was a statistically significant difference in bone height mean values between different follow-up periods within each thread design group $(\mathrm{P}<0.001$ and $\mathrm{P}<0.001$, respectively). Within both groups, the mean bone height was significantly the highest at baseline, followed in significantly descending order by 6,12 and 18 months.

TABLE (2): Mean \pm SD and P-value for comparison of crestal bone height $(\mathrm{mm})$ between both groups at each follow-up period.

\begin{tabular}{|c|c|c|l|}
\hline & $\begin{array}{c}\text { Group A } \\
\text { (Conventional } \\
\text { macro-thread } \\
\text { design) }\end{array}$ & $\begin{array}{c}\text { Group B } \\
\text { (Crestal micro- } \\
\text { thread design) }\end{array}$ & P-value \\
\hline Baseline & $12.10 \pm 0.08^{\mathrm{a}}$ & $12.12 \pm 0.08^{\mathrm{a}}$ & $0.693 \mathrm{NS}$ \\
\hline 6 months & $11.60 \pm 0.11^{\mathrm{b}}$ & $11.66 \pm 0.07^{\mathrm{b}}$ & $0.341 \mathrm{NS}$ \\
\hline $\mathbf{1 2}$ months & $11.17 \pm 0.07^{\mathrm{c}}$ & $11.26 \pm 0.10^{\mathrm{c}}$ & $0.215 \mathrm{NS}$ \\
\hline $\mathbf{1 8}$ months & $10.80 \pm 0.08^{\mathrm{d}}$ & $10.97 \pm 0.07^{\mathrm{d}}$ & $0.023^{*}$ \\
\hline P-value & $<0.001^{*}$ & $<0.001^{*}$ & \\
\hline
\end{tabular}

*: significant at P $\leq 0.05 ;$ NS: non-significant at P>0.05

Means with different superscript letters within each column are statistically significantly different at $P \leq 0.05$

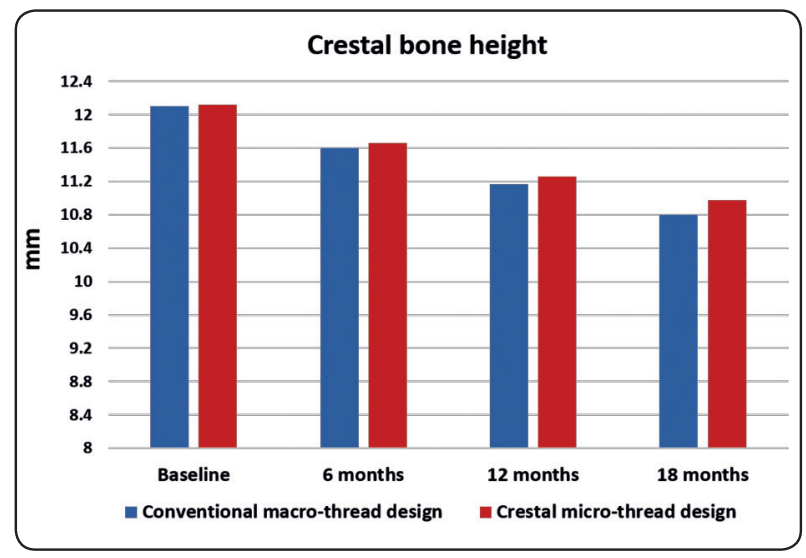

Fig. (9): Column chart showing the bone height (mm) mean values of both groups at different follow-up periods. 


\section{DISCUSSION:}

Threads design greatly increase implant surface area, optimize stress distribution and enhance implant primary stability. In addition to threads shape; pitch is another important geometric factor that influences bone-to-implant contact and biomechanical load distribution. ${ }^{15}$ Thread pitch is defined as the distance between two neighboring threads (distance from the center of the thread to the center of the next thread), measured on the same side of the axis. It also refers to the number of threads per unit length. Therefore, when implants have similar length, smaller pitch indicates greater threads number and consequently greater surface area. ${ }^{16}$

Primary stability of the implants mainly depends on the contact between bone and implant, pressfit of the implant into the osteotomy, mechanical engagement with cortical bone and affected by three major factors: bone quantity and quality, the mechanical shape of the fixture and the surgical procedure. Secondary stability involves initial healing process around the implant fixture, and it is influenced by primary stability process of osseointegration resulting from regeneration and remodeling of the bone and tissue around the inserted implants. ${ }^{17-19}$

Another way to quantitatively evaluate the primary stability, in addition to insertion torque, is resonance frequency. A way to measure resonance frequency is through the Osstell device with values calculated in ISQ and set on a scale ranging from 1 to 100 . According to previous studies, a stable implant usually has a (ISQ) resonance frequency value of more than 65 and an ISQ $<50$ could indicate a potential risk of failure. ${ }^{20-22}$

In this study, the crestal micro-threads design implants had an ISQ of $67.87 \pm 1.16,64.12 \pm$ $1.53,68.06 \pm 0.51,70.50 \pm 0.61$ and $73.43 \pm 1.34$ throughout the follow up period which is indicative of good primary stability. ISQ mean values were statistically higher than the conventional macro- threads design implants model which recorded an ISQ of $64.75 \pm 1.59,61.62 \pm 1.26,65.43 \pm 1.79$, $68.53 \pm 1.96$ and $71.00 \pm 1.44$ and higher than 65 , in other words, stable implant.

However, it must be pointed out that the mean values of primary stability obtained in this type of bone (maxillary premolar area) were quite high. This result was certainly determined by the careful insertion protocol followed, with under-preparation of surgical sites, but it was also determined by the macro-topographical characteristics of the implants used. In fact, in the present work, tapered implants have been used with self-tapping screw design. This shape may provide a better anchorage to bone, greater degree of bone compaction and a more uniform distribution of forces, thus better primary stabilization. Previous studies have already demonstrated that tapered implants tend to have higher ISQ values than cylindrical ones, the presence of a crestal micro-threads design could be a further positive element, to facilitate the stabilization of fixture in difficult situations. ${ }^{23,24}$ and this may explain the higher mean values of implant stability of group B compared to group A. Another study claimed that penetrating implants (self-drilling), usually designed with vertical cutting blades in the apical third of the implant and which can increase the primary stability. ${ }^{25}$

The higher implant primary stability mean values obtained in this study from crestal micro-threads design implant may be due to the mechanical engagement of implant fixture to the surrounding bone. It is affected not only by the quantity and quality of the available bone, but also by the implant dimensions, shape and design. Secondary stability comes from regeneration and remodeling of the bone and tissue around the implant after insertion, and it mainly depends on the micro/nano-topographical features of the implant; however, it seems to be highly dependent on the primary stability. ${ }^{13}$

Moreover, another very important observation was obtained from this study is that, in both groups 
of patients, there was no decrease or sudden drop in the stability values (ISQ) was found during healing period. This finding goes with what is reported in the literature. ${ }^{13}$ Other studies, in fact, reported a drop in the ISQ values in the healing phase (after 2 to 6 weeks of implant insertion) ${ }^{26-28}$. In our present study, the ISQ values drop was not observed and stayed very stable in the first two months of the healing time (the most critical phase for implant stabilization).

On the other hand, a study of 24 miniature pigs showed that no significant difference in removal torque value or bone to implant contact was found between implants with and without micro-threads, and the existence of micro-threads has no effect on mechanical and histological implant stability. ${ }^{29}$

In this study decreasing number of drillings through osteotomy preparation results in greater bone compression around implant body in addition to greater implant/bone contact surface; may justify the high insertion torque and suggesting greater primary stability. These results are contrary to those commonly recorded in many other studies conducted in self tapping implants, which have reported that the presence of cutting regions reduces friction and minimizes insertion torque. ${ }^{6,30}$

Lan et al. ${ }^{31}$ carried out a biomechanical analysis of alveolar bone stress around implants with different thread designs. Their results suggested that a thread pitch exceeding $0.8 \mathrm{~mm}$ is appropriate for a screwed implant and that for clinical cases requiring greater bone-implant interface trapezoid threaded implants with a thread pitch of $1.6 \mathrm{~mm}$ were more stable and generated less stress than other thread designs.

Depending on the dimension of different surface characteristics, implant surface roughness is divided into macro, micro and nano roughness. An appropriate macro roughness can directly improve the initial implant stability and long-term fixation by mechanical interlocking of the rough surface irregularities and the bone..$^{32}$ This study was done to investigate whether the micro-thread at the implant neck affected the peri-implant marginal bone level. CBCT computer software was used to accurately and reliably measure bone height around the implants immediately after surgery, after prosthesis delivery and 1 year after functional loading to study the influence of micro-threads on changes in marginal bone under load. At the end of follow up period, less bone loss was observed in group B than in group A $10.80(\mathrm{SD} \pm 0.08) \mathrm{mm}$ versus, 10.97(SD $\pm 0.07) \mathrm{mm}$, with significant differences were found between the two groups. However, bone loss at both groups' peri-implant sites was within the success criteria established by Albrektsson et al. ${ }^{33}$

The present study was aimed to investigate the effect of thread size on the marginal bone loss around implants. In particular the effect of macroand micro-threads in the implant neck area. To minimize the influence of the peri-implant mucosa and plaque accumulation on bone loss, oral hygiene instructions were provided to the patients and periodic clinical examinations of the peri-implant mucosa and professional plaque control were performed. The average bone losses in Groups A and $\mathrm{B}$ were 1.3 and $1.15 \mathrm{~mm}$, respectively, after 1 year of functional loading $(\mathrm{P}>0.05)$ with statistical significant higher bone loss in group $\mathrm{A}$, bone loss was less than $2 \mathrm{~mm}$ at both groups which indicated that macro-threads that begin at the top of the implant neck can be assumed to distribute stress under load and to maintain the marginal bone as much as micro-threads.

Peri-implantmarginalboneloss of group B (crestal micro-threads design implants) was significantly lower than of group A (conventional macro-threads design implants). Considering the smaller marginal bone changes, it could have contributed to the effect of the micro-threads in maintaining the bone level. Studies have showed the influence of surface structure on bone-to-implant interface against the marginal bone loss. Studies have verified the advantages of micro-thread on the coronal portion of fixture over the smooth neck fixture, in terms of 
bone-to-implant contact maintenance and marginal bone level preservation. ${ }^{11,12}$

In a 3-year prospective study performed on implants with different neck designs done by Lee et al. $2007^{34}$, it was reported that use of micro-threads in the implant neck area can reduce peri implant marginal bone loss.

Another study found that implants with threads that began at the top showed less bone loss than otherwise-identical implants where the threads began $0.5-\mathrm{mm}$ from the top (Song et al. 2009) ${ }^{1}$. These results indicate that the presence or absence of threads and the thread location can affect the marginal bone preservation.

Retentive elements such as micro-threads at the implant neck are necessary to preserve and maintain the peri-implant marginal bone. Micro-threads located at the implant neck greatly increases the ability of an implant to resist axial loads, moreover, the mechanical stimulus provided by the micro-threads helps to preserve peri-implant marginal bone. ${ }^{34-36}$

Studies with finite element analysis (FEA) indicate that the micro-threaded implant model has higher compression and less shear stress at the crestal cortical bone adjacent to the implant and so can reduce marginal bone resorption. ${ }^{37-39}$

However, on the other hand, a finite element study compared the effect of thread depth on marginal bone found no significant difference in the stress distribution when a thread depth of 0.1 or 0.4 $\mathrm{mm}$ was used, so long as the thread profile was favorable (Hansson \& Werke 2003). ${ }^{40}$ The results of studies for thread pitch are controversial, another finite element study showed that, implants with a $0.5-\mathrm{mm}$ pitch had a more favorable stress distribution than those with a pitch of 1.0 or 1.5 , and the maximum effective stress gradually decreased with decreasing thread pitch (Motoyoshi et al. 2005). ${ }^{41}$ Moreover, another study also using finite element study revealed that thread pitch of $0.18-0.30 \mathrm{~mm}$ was considered as optimal from a biomechanical point of view (Kong et al. 2008). ${ }^{42}$
Multiple studies demonstrated that implants with smaller pitch showed the greater surface area and better stress distribution particularly in low-density bone. Orsini et al. ${ }^{7}$ conducted an animal study placing "narrow-pitch" $(0.5 \mathrm{~mm})$ and "wide-pitch" $(1.7 \mathrm{~mm})$ implants in a sheep iliac crest model. The findings suggested that the greater bone-implant contact BIC gained by reducing thread pitch could improve initial anchorage and primary stability in cancellous bone. Another animal study performed by Chung et al. also revealed that implants with a $0.6-\mathrm{mm}$ pitch created more crestal bone resorption than those with a $0.5-\mathrm{mm}$ pitch. In addition, the same results were found in the studies using FEA models. Authors independently reported that smaller pitch presented better load resistance and less effective stress in their three-dimensional FEA models. ${ }^{41,44,45}$

It was proved in the literature reviews that the first thread located on the implant fixture has the ability to convert the shear force into a compressive force. ${ }^{46}$

The reported marginal bone loss around microthreaded implants after 1 year of functional loading are varied and range from 0.05 to $1.6 \mathrm{~mm} .{ }^{14,47}$ which was similar to the findings of this results

It was reported that, after three years of functional loading of implants with micro-thread design, the marginal bone loss was lower than those with rough and machined surfaces. Accordingly, retention elements were said to inhibit marginal bone loss. It was observed that the differences in the design and surface configurations of the implant collar in the different implant systems could influence the amount of marginal bone loss. ${ }^{48}$

Another study revealed that the micro-thread profile seemed to be more important than the microthread length along the neck of implant fixture in reducing loading stresses exerted on the surrounding bone. Fine micro-threads on a $3 \mathrm{~mm}$ implant neck showed consistently higher cortical bone stress than other implant fixtures with $1 \mathrm{~mm}$ and $2 \mathrm{~mm}$ microthreads neck. ${ }^{49}$ 
The combination of more than one retentive element such as micro-threads with rough-surface implants could achieve a lot of advantages such as increased implant-to-bone contact and improved stress distribution. However, the exposure of rough-surface implants to the oral environment can accelerate biofilm formation and facilitate plaque retention, increasing the risk of periimplant mucositis and peri-implantitis. Therefore, such potential biologic complications related to micro-threads should be taken into account when formulating a treatment plan for patients with a high susceptibility to peri-implantitis. ${ }^{50,51}$

On the other hand, a study was done to compare the effect of thread size on the implant neck area for 1 year of function revealed that there was no significant difference between implant with macroand micro-neck thread in terms of marginal bone loss after 1 year of loading. ${ }^{52}$

Finally, surface roughness or the retentive elements like the micro-thread could increase the resistance of marginal bone against the bone loss by the interlocking force between the implant surface and the crestal bone..$^{53}$ The amount of bone loss was minor, likely because both groups of implants had internal conical seal type fixture-abutment connections, which are advantageous in marginal bone preservation. ${ }^{14,54,55}$. It is possible that the beneficial effects of the rough surface and conical fixture-abutment interface on the marginal bonelevel maintenance overwhelmed the additional effects of the micro-thread. ${ }^{54}$ Alternatively, macrothreads that begin at the top of the implant neck can be assumed to distribute stress under load and to maintain the marginal bone as much as microthreads.

\section{CONCLUSIONS}

Within the limitations of the study, it may be concluded that; Less peri-implant marginal bone loss was observed around implants with crestal micro-threads design implants compared to those with conventional threads design implants in conjunction with higher implant stability values.

\section{REFERENCES}

1. Song, D.W., Lee, D.W., Kim, C.K., Park, K.H. \& Moon, I.S. Comparative analysis of periimplant marginal bone loss based on microthread location: a 1-year prospective study after loading. Journal of Periodontology.2009; 80: 1937-1944.

2. Barfeie A, Wilson J and Rees J. Implant surface characteristics and their effect on osseointegration. British Dent J. 2015; 218: E9; 1-9

3. Özkır SE, Atay A and Köroğlu A. MICROTHREAD CONCEPT IN DENTAL IMPLANTS. Int. J Sci and Techno.2014; 22 (3):1549-1553.

4. Dos Santos MV, Elias CN, Cavalcanti Lima JH. The effects of superficial roughness and design on the primary stability of dental implants. Clin Implant Dent Relat Res 2011; 13:215-223.

5. Jung UW,KimS, Lee IK,KimML, Lee JS,KimHJ. Secondary stability of microthickness hidroxyapatite-coated dental implants installed without primary stability in dogs. Clin Oral Implants Res 2014; 25:1169-1174.

6. Freitas AC Jr, Bonfante EA, Giro G, Janal MN, Coelho PG. The effect of implant design on insertion torque and immediate micromotion. Clin Oral Implants Res 2012; 23:113-118.

7. Orsini E, Giavaresi G, Trirè A, Ottani V, Salgarello S. Dental implant thread pitch and its influence on the osseointegration process: an in vivo comparison study. Int $\mathbf{J}$ Oral Maxillofac Implants 2012; 27:383-392.

8. Desai SR, Desai MS, Katti G, Karthikeyan I. Evaluation of design parameters of eight dental implant designs: a twodimensional finite element analysis. Niger J Clin Pract 2012; 15:176-181

9. Abuhussein H, Pagni G, Rebaudi A, Wang HL. The effect of thread pattern upon implant osseointegration. Clin Oral Implants Res 2010;21:129-36.

10. Masuda T, Yliheikkilä P K, Felton D A, Cooper L F. Generalizations regarding the process and phenomenon of osseointegration. Part I. In vivo studies. Int J Oral Maxillofac Implants 1998; 13: 17-29.

11. Berglundh, T., Abrahamsson, I. \& Lindhe, J. Bone reactions to longstanding functional load at implants: an experimental study in dogs. Journal of Clinical Periodontology. 2005; 32: 925-932. 
12. Abrahamsson, I. \& Berglundh, T. Tissue characteristics at microthreaded implants: an experimental study in dogs. Clinical Implant Dentistry and Related Research. 2006; 8: 107-113.

13. Gomes RZ, de Vasconcelos MR, Guerra IM, 1 de Almeida RA and Felino AC. Implant Stability in the Posterior Maxilla: A Controlled Clinical Trial. Biomed Res Int. 2017; 5:1-11.

14. Engquist, B.,A ${ }^{\circ}$ strand, P., Dahlgren, S., Engquist, E., Feldmann, H. \& Gro“ndahl, K. Marginal bone reaction to oral implants: a prospective comparative study of Astra Tech and $\mathrm{Bra}^{\circ}$ nemark System implants. Clinical Oral Implants Research. 2002; 13: 30-37.

15. Ryu HS, Namgung C, Lee JH, Lim YJ The influence of thread geometry on implant osseointegration under immediate loading: a literature review. J Adv Prosthodont 2014;6:547-554

16. Misch CE, Steignga J, Barboza E, Misch-Dietsh F, Cianciola LJ, Kazor C. Short dental implants in posterior partial edentulism: a multicenter retrospective 6-year case series study. J Periodontol 2006;77:1340-1347.

17. Dursun CK, Dursun E, Eratalay K, Orhan K, Tatar I, Baris E, et al. Effect of Porous Titanium Granules on Bone Regeneration and Primary Stability in Maxillary Sinus: A Human Clinical, Histomorphometric, and Microcomputed Tomography Analyses.J Craniofac Surg. 2016; 27(2):391-397.

18. Sagheb K, Kumar VV, Azaripour A, Walter C, Al-Nawas B, Kämmerer PW. Comparison of conventional twist drill protocol and piezosurgery for implant insertion: an ex vivo study on different bone types. Clin Oral Implants Res. 2017;28(2):207-213

19. Lozano-Carrascal N, Salomó- Coll O, Gilabert-Cerdà M, Farré-Pagés N, Gargallo-Albiol J, Hernández-Alfaro F. Effect of implant macro-design on primary stability: A prospective clinical study. Med Oral Patol Oral Cir Bucal. 2016; 21(2): 214-221.

20. Atsumi M, Park SK, Wang HL. Methods used to assess implant stability: current status. Int J Oral Maxillofac Implants 2007; 22:743-754.

21. Kim DS, Lee WJ, Choi SC, et al. Comparison of dental implant stabilities by impact response and resonance frequencies using artificial bone. Med Eng Phys 2014; $36: 715-720$

22. Valente ML, Tornavoi de Castro D, Shimano AC, Lepri $\mathrm{CP}$, and Cândido dos Reis A. Analyzing the Influence of a New Dental Implant Design on Primary Stability. Clin Implant Dent Relat Res. 2016; 18 (1): 168-173.
23. Han $\mathrm{CH}$, Mangano F, Mortellaro $\mathrm{C}$ and Park KB, "Immediate loading of tapered implants placed in postextraction sockets and healed sites," J Craniofacial Surg. 2016; 27(5): 1220-1227.

24. Alshehri M and Alshehri F, "Influence of Implant Shape (Tapered vs Cylindrical) on the Survival of Dental Implants Placed in the Posterior Maxilla: a systematic review," Implant Dentistry. 2016; 25(6): 855-860.

25. Toyoshima T, Wagner W, Klein MO, Stender E, Wieland $\mathrm{M}$ and Al-Nawas B. Primary stability of a hybrid self-tapping implant compared to a cylindrical non-self-tapping implant with respect to drilling protocols in an ex vivo model. Clin Implant Dent Relat Res 2011; 13:71-78.

26. Kim JM, Kim SJ, Han I, Shin SW, and J.-J. Ryu, “A comparison of the implant stability among various implant systems: clinical study," Journal of Advanced Prosthodontics, 2009; 1(1): 31-36.

27. Rodrigo D, Aracil L, Martin C, and Sanz M, "Diagnosis of implant stability and its impact on implant survival: a prospective case series study," Clinical Oral Implants Research. 2010; 21(3): 255-261.

28. Pagliani L, Sennerby L, Petersson A, Verrocchi D, Volpe $\mathrm{S}$, and Andersson P, "The relationship between resonance frequency analysis (RFA) and lateral displacement of dental implants: an in vitro study, Journal of Oral Rehabilitation. 2013 ; 40(3): 221-227.

29. Kwon YS, Namgoong H, Kim JH, Cho IH, Kim MD, Eom TG, et al. Effect of microthreads on removal torque and bone-to-implant contact: an experimental study in miniature pigs. J Periodontal Implant Sci 2013; 43:41-46.

30. Chong L, Ahmed K, Jon BS, John G. Effect of implant design on initial stability of tapered implants. J Oral Implantol 2009; 35:130-135.

31. Lan T H, Du J K, Pan C Y, Lee H E, Chung W H. Biomechanical analysis of alveolar bone stress around implants with different thread designs and pitches in the mandibular molar area. Clin Oral Investig 2012; 16: 363-369.

32. Shalabi M M, Gortemaker A, Van’t Hof M A, Jansen J, Creugers N H. Implant surface roughness and bone healing: a systematic review. J Dent Res 2006; 85: 496-500.

33. Albrektsson T, Zarb G, Worthington P, Eriksson AR. The long-term efficacy of currently used dental implants: A review and proposed criteria of success. Int J Oral Maxillofac Implants. 1986;1:11-25. 
34. Lee DW, Choi, YS, Park, KH, Kim, CS and Moon, IS. Effect of microthread on the maintenance of marginal bone level: a 3-year prospective study. Clinical Oral Implants Research. 2007; 18: 465-470.

35. Palmer RM, Palmer PJ, Smith BJ. A 5-year prospective study of astra single tooth implants. Clin Oral Implants Res 2000; 11:179-182.

36. Jin ZH, Peng MD and Li Q. The effect of implant neck microthread design on stress distribution of peri-implant bone with different level: A finite element analysis.J Dent Sci.2019; 12(3):1-6

37. Schrotenboer J, Tsao YP, Kinariwala V, Wang HL. Effect of microthreads and platform switching on crestal bone stress levels: a finite element analysis. J Periodontol 2008;79:2166-72.

38. Meric G, Erkmen E, Kurt A, Eser A, Celik G. Biomechanical evaluation of a fiber-reinforced composite prosthesis supported by implants with and without a microthread collar design. J Dent Sci 2010;5:201-208.

39. Hudieb MI, Wakabayashi N, Kasugai S. Magnitude and direction of mechanical stress at the osseointegrated interface of the microthread implant. J Periodontol 2011;82:1061-1070.

40. Hansson, S. \& Werke, M. The implant thread as a retention element in cortical bone: the effect of thread size and thread profile: a finite element study. Journal of Biomechanics. 2003; 36: 1247-1258.

41. Motoyoshi, M, Yano S, Tsuruoka T and Shimizu N. Biomechanical effect of abutment on stability of orthodontic mini-implant. A finite element analysis. Clinical Oral Implants Research 2005; 16: 480-485

42. Kong L, Hu K, Li D, Song Y, Yang J, Wu Z. and Liu B. Evaluation of the cylinder implant thread height and width: a 3-dimensiona finite element analysis. Int J Oral and Maxillo Imp. 2008; 23: 65-74.

43. Chung SH, Heo SJ, Koak JY, Kim SK, Lee JB, Han JS, Han CH, Rhyu IC, Lee SJ. Effects of implant geometry and surface treatment on osseointegration after functional loading: a dog study. J Oral Rehabil 2008; 35: 229-236.

44. Chun HJ, Cheong SY, Han JH, Heo SJ, Chung JP, Rhyu IC, Choi YC, Baik HK, Ku Y, Kim MH. Evaluation of design parameters of osseointegrated dental implants using finite element analysis. J Oral Rehabil 2002; 29: 565-574.
45. Ma P, Liu HC, Li DH, Lin S, Shi Z, Peng QJ. Influence of helix angle and density on primary stability of immediately loaded dental implants: three-dimensional finite element analysis. Zhonghua Kou Qiang Yi Xue Za Zhi 2007;42:618- 621.

46. Oh TJ, Yoon J, Misch CE, Wang HL. The causes of early implant bone loss: Myth or science? J Periodontol 2002; 73:322-333.

47. Puchades-Roman L, Palmer RM, Palmer PJ, Howe LC, Ide $\mathrm{M}$ and Wilson RF. A clinical, radiographic, and microbiologic comparison of astra tech and Bra ${ }^{\circ}$ nemark single tooth implants. Clin Implant Dent Relat Res 2000;2:78-84.

48. Lee SY, Piao CM, Koak JY, Kim SK, Kim YS, Ku Y, Rhyu IC, Han CH, and Heo SJ. A 3-year prospective radiographic evaluation of marginal bone level around different implant systems. J Oral Rehab 2010; 37:538-544.

49. Golmohammadi S, Eskandari A, Movahhedy MR, Shirmohammadi a and Amid R. The effect of microthread design on magnitude and distribution of stresses in bone: A three-dimensional finite element analysis. Dent Res J 2018;15:347-353.

50. Teughels W, Assche NV, Sliepen I, Quirynen M. Effect of material characteristics and/or surface topography on biofilm development. Clin Oral Implants Res 2006; 17:68-81.

51. Cosyn J, Sabzevar MM, De Wilde P, De Rouck T. Twopiece implants with turn ed versus microtextured collars. J Periodontol 2007;78:1657-1663.

52. Young-Il Kang, Dong-Won Lee, Kwang-Ho Park and IkSang Moon. Effect of thread size on the implant neck area: preliminary results at 1 year of function. Clin. Oral Impl. Res. 2011; 1-5.

53. Hansson, S. The implant neck: smooth or provided with retention elements. A biomechanical approach. Clinical Oral Implants Research 1999; 10: 394-405.

54. Hansson, S. Implant-abutment interface: biomechanical study of flat top versus conical. Clinical Implant Dentistry and Related Research. 2000; 2: 33-41.

55. van Steenberghe, D., De Mars, G., Quirynen, M., acobs, R. $\&$ Naert, I. A prospective split mouth comparative study of two screw-shaped self-tapping pure titanium implant systems. Clinical Oral Implants Research. 2000; 11: 202-209. 